\title{
Consumers' Attitude toward Islamic Insurance Services (Takaful) Patronage in Kano Metropolis, Nigeria
}

\author{
A. A. Maiyaki ${ }^{1} \&$ H. Ayuba $^{2}$ \\ ${ }^{1}$ Department of Business Administration and Entrepreneurship, Bayero University, Nigeria \\ 2 NNDC-ICAN Study Centre, Murtala Mohammed Library Complex, Nigeria \\ Correspondence: H. Ayuba, NNDC-ICAN Study Centre, Murtala Mohammed Library Complex, Ahmadu Bello \\ Way, Nassarawa, Kano State, Nigeria. E-mail: ayuhab2@gmail.com or habibuayuba@yahoo.co.uk
}

\author{
Received: January 12, 2015 Accepted: February19, $2015 \quad$ Online Published: March 28, 2015 \\ doi:10.5539/ijms.v7n2p27 URL: http://dx.doi.org/10.5539/ijms.v7n2p27
}

\begin{abstract}
Islamic Insurance (Takaful) is the insurance practice that is established based on ethical faith to provide a risk management product for consumers whose belief has discouraged them to patronize the conventional insurance services.Takaful products are developed to be free from 3 in-built principles (interest, uncertainty and gambling element) that have disqualified any financial transaction to be Sharia compliant. Thus, the paper is aimed at examining the factors that influence the consumers' attitude toward Takaful services patronage in Kano Metropolis, Nigeria. To this end, the study examines the extent to which consumers' awareness, perception of Takaful services and the trust and confidence they reposed on Takaful Operators have significant relationship with their attitude towards Takaful services patronage. A structured questionnaire was the only instrument used in collecting the data. Although, the population of the study is indefinite, 384 subjects are administered with the questionnaires using judgmental sampling technique and the employment status of the respondents was the basis for the selection and inclusion of the respondents in the study. The data was analyzed using multiple- regression with SSPS version 17. The paper found that awareness, perception, trust and confidence are significantly related to the consumers' attitude toward Takaful services patronage. It was, therefore, recommended that an attitudinal change campaign is required and rigorous marketing campaign should be embarked upon to create awareness of Takaful service and its Operators. Hence, trust and confidence of people should be won and built in favor of Takaful services.
\end{abstract}

Keywords: Islamic insurance, Takaful, awareness, perception, trust, confidence, attitude

\section{Introduction}

Consumers' patronage attitude is a psychological tendency that evaluates their related entity with some degree of favor or disfavor. Thus the attitude predicts consumption behavior. It is also guided and governed by more overarching value systems which encompass central dispositions applicable to a wide range of situations, context and behavior. It is the consumers' context specific dispositions that link personal value toward actual consumption behavior (Wang, Dou, \& Zhou, 2008). Consumer's tradition and culture, of course, play significant role in shaping their mindset (attitude) in anything materials (products/insurance) in this global world. Their global view is largely dependent on their attitude which is a product of culture and tradition. Attitude toward anything such as life style, education, risks and more importantly the consumption habit are made by consumers to simply make their choices about what they interact with or consume like products or services. Consumers consume many products and services for them to satisfy their pressing needs to survive and prosper privately or in business. The perceived pressing needs of consumers in the contemporary world, as observed (by who?), might not be far away from the need for security, security for life and properties. This calls for the flourishing of many risk management products at the services of consumers that can allow them to transfer the risk attributable to lack of security, to avoid it or to accept it. Among the available products that can enable the people, especially business community to transfer and mitigate their risk which has become so pronounced is insurance services.

With its perfectly competitive market status, Nigerian Insurance Industry has provided choices for people whose ethical and religious conscience permits them to consume only ethical products and services. The conventional insurance services available in the Industry are found to be ill-suited to the culture, tradition, ethics and religion of Muslim population who are very largely predominantly in the Northern part of the country, more particularly 
in Kano Metropolis, Nigeria. This creates the needs for risk management service that can be accepted and patronized by the people of Kano who are largely business people. Consumers' patronage of a product and service, according to MdRazak, Idris, Yusof, Ja'apar and Ali (2013), is a very complicated process involving societal attitudes. This made the consumers' attitude to be a significant factor in determining product/service patronage particularly Islamic Insurance (Takaful) services consumption (Ayuba, 2014).

Takaful as reported by MdRazak et al. (2013), based on Bank Negara's definition, isan insurance concept in Shariahwhereby a group of participants mutually agree among themselves to guarantee each other against defined loss or damage that may inflict upon any of them by contributing as Tabarru (donation) in the Takaful fund. A provision is made by a group of persons where each personsingle-handedly, who is in danger of some loss, the incidence of which cannot be foreseen, contribute funds. The scheme determines that should a loss befall on any of the participants, the contributed fund would be distributed over the whole group. Takaful, in general, is a system of Islamic insurance based on the principle of mutual cooperation (Ta'awun) and donation (Tabarru), where the risk is shared collectively and voluntarily by the group of participants. It is derived from an Arabic word meaning joint guaranteeguaranteeing each other or one another (MdRazak et al., 2013; Ayuba, 2014). It is an arrangement by a group of people with common intereststo guarantee and protect themselves from certain defined misfortunes such as premature death, disability, ageing, sickness and propertydamages, fire and so on (Ayuba, 2014).

Under the schemes, participants mutually agree to guarantee and to protect one another against a defined loss or damage, by jointly providing financial assistance to any member sufferingfromaloss. Takaful literally means shared responsibility, shared guarantee, collective assurance and mutual undertakings. Thus, Sharia compliant insurance is based on shared responsibility, mutual co-operationandsolidarity. The Takaful business is designed to protect the participants against a defined risk. It is a scheme that is free from elements of Gharar (uncertainty) in respect of premium and coverage, Maisir (Gambling) and Riba (interest) which are the three (3) cardinal principles of Islamic Finance (SECP, 2010; MdRazak et al., 2013; Ayuba, 2014).

Takaful business has come to Nigerian Insurance industry not much longer than a decade. Ayuba (2014) reported that the concept of Takaful came to be known in Nigeria, somewhere around 2003, the time when African Alliance Insurance Plc introduced its family Takaful products. Cornerstone insurance Plc,similarly, open its shop in 2009 by setting up a division called Halal Nigeria Limited which offers general Takaful products into Nigerian insurance market. Niger insurance Plc has later provided ranges of Sharia complied insurance products in 2008/2009. The presence of these insurance companies offering Takaful services in the Nigerian Insurance Industry and Kano Market indicate, as observed, that they are at early stage of their life span. Consumers' patronage of a product/service research, as reported by MdRazah et al. (2013), however, has provided important insights in explaining the success or failure of new products or services. They, therefore, argued that, although, various product-specific drivers have been proposed, mostly in connection with marketing mix variables and product characteristics, yet, consumer's acceptance orpatronage reflects of his experience in using a product. This result to this study can enable understanding of consumers' attitude upon the Takaful patronage in Kano Metropolis, Nigeria.

\section{Literature Review}

Theoretically, the practice of Islamic insurance is built on the basis of contract of profit and loss sharing (Aqd al - Mudharabah) and unilateral contract of donation (Aqd al Tabarru). Mudharabah theory states that the funds will be contributed by two or more people for the purpose of investment at which the profit or loss will be shared among the participants. But, the doctrine of Tabarru, however, is synonymous with that of Al-sadaqah (charity), al-Hiba (gift) and Al-Khairat (donation); wherein anything once given away as donation in favor of something or someone, the donated property cannot generally be retracted. The donor automatically loses title over the donated property soon after it is made as al-Tabarru or Al-Sadaqah or al-Khairat or Al-Hiba. Takaful business is divided into two categories: Family Takaful and General Takaful. Family Takaful plan is a Sharia compliant counterpart of conventional life insurance. It consists of partly mutual funds for the risk precaution and the partly part of saving funds for investment in a Sharia Halal business. The general Takaful plan, however, is solely provided on a short term mutual indemnity basis and is usually one year, without the saving aspect. Should there be a net surplus in the general Takaful fund, it shall be shared between the participants and the operator (Ayuba, 2014).

On the other hand, attitude of consumers, according to Kotler (2000), settles into a consistent pattern: to change it, may require major adjustments in otherfactors and other attitudes. As a tool which puts people into a frame of mind of liking or disliking an object, product or service; moving toward or away from it, understanding its 
factors that can build or change an attitude of customers is the motive of every provider of services or product, Takaful operators are inclusive. This might be the trigger that has motivated Yusuf, Gbodamosi and Hamidu (2009) trying to establish the attitude of Nigerian toward insurance service. Their study confirmed that Nigerians hold negative attitude toward insurance services. Because, they argue that consumers from different culture rely on different factors during the process of relationship development especially with the service providers. These cultural factors reliance are what have prompted Nigerians to exhibit different behavioral reaction to insurance services. This study, therefore, examines public attitude upon the Islamic insurance services. Unlike Yusuf et al. (2009) who studied conventional insurance and their respondents were drawn from Lagos, one of the Nigerian biggest commercial city in the south where the predominant people are Non-Muslim, this research on the other hand is on Islamic insurance and respondents are drawn from Kano, one of the biggest commercial city in the northern Nigeria and majority of the populace are Muslims.

Ayuba (2014) discovered non-economic factors determining Takaful consumption in Kano Metropolis. This study measures the effect of public awareness; public perception and public trust and confidence reposedonTakaful Operators on public attitude toward Takaful patronage in Kano metropolis. Literatures such as (Taylor, 2005; Rahman, 2009; \& Ayuba, 2014) have reported that at both individual and corporate levels, awareness of Takaful services among Muslim is essential; because, there are still some consumers in some markets who are unable to distinguish Takaful from conventional insurance. The doubt, on the part of the Muslim Ummah and even the Non-Muslims who want to patronize ethical products, about Takaful system has been the reason for the slow growth of the Takaful business. Hence, awareness of consumers over a given product or services, is presumed to play significant role in shaping their attitude to favor a service/product or disfavor it.

Similarly, Bello and Ayuba (2014) have noted that consumers' perception is the function and reflection of their awareness of the offerings (Takaful) and the trust level built by the consumer on the services providers (Takaful Operators). This explains the position that marketers hold with regard to consumers' product/services decision process. Marketers argue that perception enables consumer to select, organize and interpret the information inputs to create a meaningful picture of the world. What one perceives is subjective and can be substantially different from objective reality. This is due to the people selective attention (selection of what one needs); selective distortion (blockage of unnecessary stimuli) and selective retention (retention of needed stimuli). Thus, different factors operate to shape people perception which can be from the perceiver (Attitude, motives, interest, experience and expectation), the target object (Novelty, motion, sound, size, background, proximity and similarity) and the situation (time, work setting, social setting etc.) (Schiffman \& Kanuk, 2004; Kotler \& Keller, 2005; Robbins \& Judge, 2007; Akpa, 2008; Teas, 1993). If perception should influence consumers' attitude, this study tests an impact of perception of consumers on the attitude toward the Takaful services patronage.

Besides, uncertain nature of business environment in the developing countries has made the trust of the business partner to be a consideration of paramount importance. This has made it mandatory as observed for the service providers to build strong trust and confidence of the clients/customer for them to win and succeed. Bello and Ayuba (2014) have already determined the average influence of the public trust and confidence repose on the Takaful operators on income earners' perception. This study, therefore, tests whether there is significant influence between Public attitude and their trust on the service providers. It is in line with these assertions that the study wants to answer the following research questions:

1) To what extent does the awareness of consumers' has significant relationship with their attitude toward Takaful services patronage?

2) To what extent does the consumers' perception has significant relationship with their attitude toward Takaful services patronage?

3) To what extent does the trust and confidence reposed on Takaful operators by consumers have significant relationship with their attitude toward Takaful services patronage?

\subsection{Research Hypotheses}

As a statement of logical guess, hypothesis replaces the possibility in the occurrence of an event under investigation. It offers solution to the research questions and tries to establish a relationship or difference between the variables involve in the investigations (Institute of Chartered Accountant of Nigeria (ICAN), 2010). It is a tentative proposition suggested as a solution to a problem or as an explanation of some phenomenon (Bichi, 2004). Thefollowing hypotheses are hereby formulated for the study.

$\mathrm{HO}_{1}$ Consumers' awareness of Takaful services is not significantly related to their attitude toward Takaful 
services patronage.

$\mathrm{HO}_{2}$ Consumers' perception on Takaful services is not significantly related to their attitude toward Takaful service patronage.

$\mathrm{HO}_{3}$ Consumers' trust and confidence reposed on Takaful operators is not significantly related to their attitude toward Takaful services patronage.

\section{Methodology of the Study}

This research is purely quantitative research. It is designed for fact findings that describe the phenomena under study. It employs explanatory survey design as an avenue to achieve the research objectives which are in line with the research question raised. This enables ascertaining the veracity of the study's hypotheses formulated.Three independent explanatory variables (Consumers' awareness, perceptionand trust and confidence reposed on Takaful operators) are identified which are measured against the dependent variable: Consumers' attitude on Takaful services patronage.Primary source of data was used and questionnaire served as the instrument of data collection. The questionnaire is subjected to validity test before employed in to full administration to the subjects. The data collected from the respondents are subjected to reliability test. Although, the population of the respondents (Gainfully employed people) in Kano Metropolis is indefinite due to poor or absence of statistical record, the people that are there in the 8 metropolitan local Government of Kano State, according to the 2006 population census, are approximately 2,828,861, (FGN Gazette 2009). This is what has informed the study to use 384 (Research Advisors, 2004 in Ayuba, 2014) subjects as a sample size. The research employs judgmental sampling technique as the method of selecting 384 respondents (at $5 \%$ margin of error and $95 \%$ level of significant) from the population of the study under the criteria that only gainfully employed consumers are included. Table 1 summarizes characteristics of the respondents.

Table 1. Sample structure

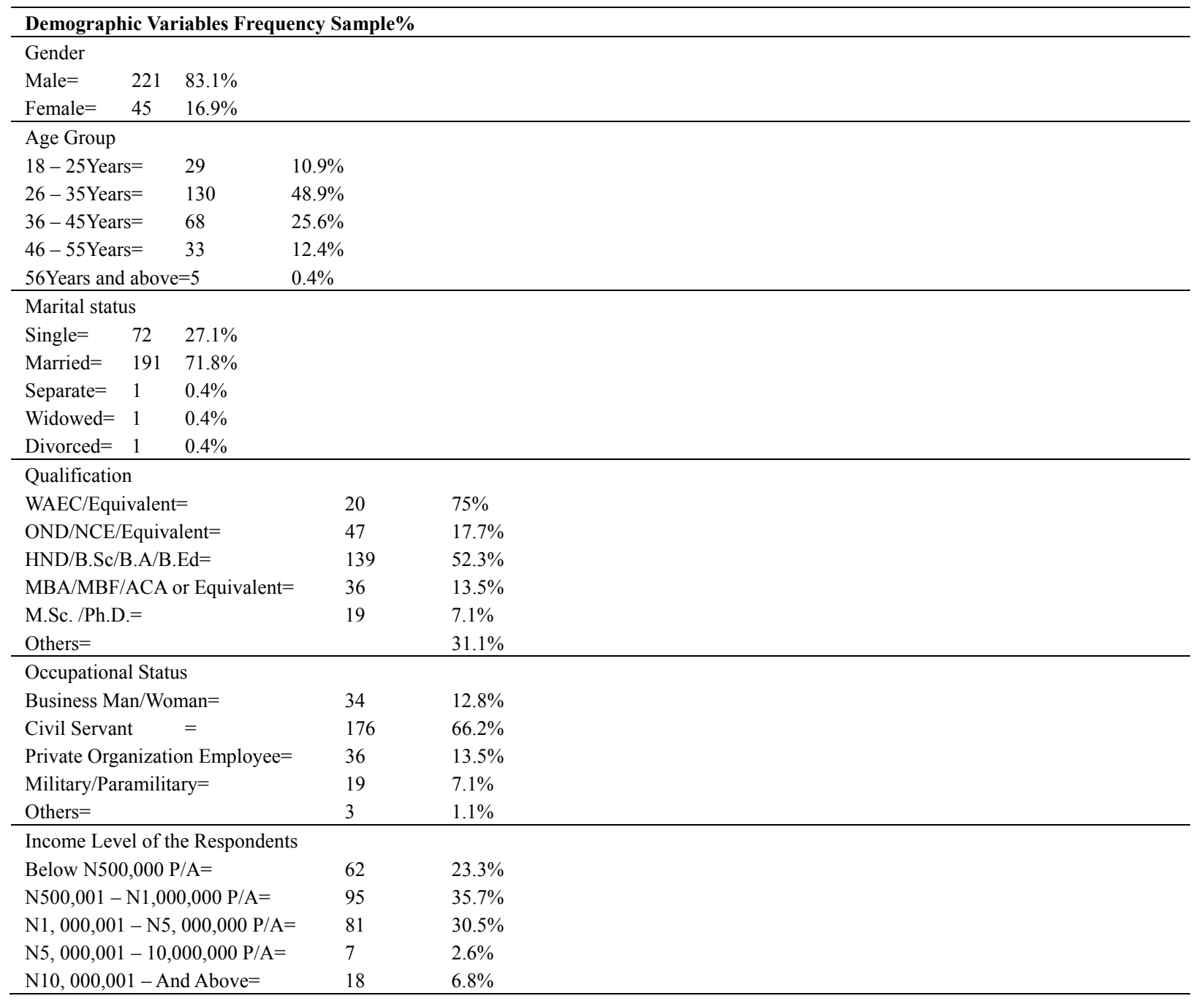




\subsection{Validity and Reliability of the Research Instrument}

The validity of the questionnaire was tested by given it to the experienced academician and managers of Takaful business to assess and determine the face and content validity of the instrument.The criteria employed in the test were: readability of the questions, language level, and the adequacy of the question and the content coverage of the subject matter. After restructuring and correction, the final copy of the questionnaire was produced for administration. The questionnaire scale is 5 points Likert scale of strongly agreed (5) to strongly disagreed (1). The reliability of the instrument was tested using Cronbach's Alpha coefficient in SSPS 17. It was found to be 0.624 for the Awareness construct; 0.705 for the Perception construct; 0.726 for the Trust construct and 0.766 for Attitude construct. This indicated that the instrument was reliable as itmet the minimum benchmark of 0.7 .

\subsection{Normality and Multi-colinearity Test of the Data Collected}

It is essential to test the normality position of the data in order to satisfy the parametric assumption of multipleregression. The Skewness and Kurtosis measurement calculated in the Table 2 indicates that the data is symmetric. The skewness values are less than \pm 1 of all the 4 constructs confirming the normality of the data. But, awareness construct is having positive Kurtosis a little bit more than \pm 1 which suggests peak of the score.

Table 2. Descriptive statistics

\begin{tabular}{llllll}
\hline & $\mathrm{N}$ & Skewness & & Kurtosis \\
\hline & Statistic & Statistic & Std. Error & Statistic & Std. Error \\
\hline AWARENESS & 255 & -.907 & .153 & 1.175 & .304 \\
ATTITUDE & 251 & -.921 & .154 & .903 & .306 \\
PERCEPTION & 256 & -.706 & .152 & .729 & .303 \\
TRUST & 255 & -.749 & .153 & .661 & .304 \\
Valid N (listwise) & 239 & & & & \\
\hline
\end{tabular}

The Multi-colinearity position among the explanatory variables shows that all the 3 variables are within acceptable level. Table 3 presents all the 3 variables as having less than 0.6 variable proportion which is accepted level of colinearity. The result is stating that the requirement of regression test is herewith met.

Table 3. Collinearity diagnostics ${ }^{\mathrm{a}}$

\begin{tabular}{llllllll}
\hline & & \multicolumn{5}{l}{ Variance Proportions } \\
\cline { 5 - 8 } Model & Dimension & Eigenvalue & Condition Index & (Constant) & AWARENESS & TRUST & PERCEPTION \\
\hline 1 & 1 & 3.931 & 1.000 & .00 & .00 & .00 & .00 \\
& 2 & .032 & 11.066 & .26 & .18 & .28 & .16 \\
& 3 & .019 & 14.536 & .47 & .43 & .32 & .31 \\
& 4 & .018 & 14.815 & .27 & .39 & .39 & .53 \\
\hline
\end{tabular}

a. Dependent Variable: ATTITUDE.

\section{Results of the Findings}

The summary output of the multiple-regression begins with the descriptive statistic which states that 239 respondents' response is used in running the result. It involves four constructs in which one (Attitude) is dependent variable and the other three are independent variables.

Table 4 reports summary of ANOVA which shows that the overall model is found to be statistically significant. The calculated F- value $=0.000$ is less than the Tabulated $5 \%$. This confirms that the 3 explanatory variables are statistically capable of predicting the dependent variable. 
Table 4. ANOVA ${ }^{\text {b }}$

\begin{tabular}{lllllll}
\hline Model & & Sum of Squares & df & Mean Square & F & Sig. \\
\hline 1 & Regression & 1460.802 & 3 & 486.934 & 79.791 & $.000^{\mathrm{a}}$ \\
& Residual & 1434.109 & 235 & 6.103 & & \\
& Total & 2894.911 & 238 & & & \\
\hline
\end{tabular}

a. Predictors: (Constant), PERCEPTION, AWARENESS, TRUST.

b. Dependent Variable: ATTITUDE.

In the model summary (Table 5) the multiple regression result presented that the coefficient $\mathrm{R}=0.710$ using all the predictors; The $\mathrm{R}^{2}=0.505$ and adjusted $\mathrm{R}^{2}=0.498$ indicates that the level of explanation between Attitude and Awareness, Perception and Trust is having average effect.

Table 5. Model summary ${ }^{\mathrm{b}}$

\begin{tabular}{|c|c|c|c|c|c|c|c|c|c|c|}
\hline \multirow[t]{2}{*}{ Model } & \multirow[t]{2}{*}{$\mathrm{R}$} & \multirow[t]{2}{*}{ R Square } & \multirow{2}{*}{$\begin{array}{l}\text { Adjusted R } \\
\text { Square }\end{array}$} & \multirow{2}{*}{$\begin{array}{l}\text { Std. Error of } \\
\text { the Estimate }\end{array}$} & \multicolumn{5}{|c|}{ Change Statistics } & \multirow[t]{2}{*}{ Durbin-Watson } \\
\hline & & & & & $\begin{array}{l}\text { R Square } \\
\text { Change }\end{array}$ & F Change & df1 & $\mathrm{df} 2$ & $\begin{array}{l}\text { Sig. F } \\
\text { Change }\end{array}$ & \\
\hline 1 & $.710^{\mathrm{a}}$ & .505 & .498 & 2.47034 & .505 & 79.791 & 3 & 235 & .000 & 1.863 \\
\hline
\end{tabular}

a. Predictors: (Constant), PERCEPTION, AWARENESS, TRUST.

b. Dependent Variable: ATTITUDE.

This implies that increases in Awareness, favorable perception and trust result to commensurate increases in the positive Public Attitude.

Besides; the standardized and un-standardized Beta (Table 6) shows the level of association of each independent explanatory variable with the dependent variable. It presents identified regression equation which helps in understanding the predictive power of each explanatory variable. For the predictor: Awareness; $y=2.084+$ $0.283 x$; Perception; $y=2.084+0.506 x$ and Trust; $y=2.084+0.525 x$. These equations can be used separably in determining the predictor values of the respective explanatory variables.

Furthermore, the standardized beta in Table 6 acts as a correlation coefficient. It determines the extent of correlation of independent variables with the dependent variable. The results show that Awareness is positively correlated with the Public Attitude. It has $29.9 \%$ capability to cause favorable Public Attitude. It is small effect but statistically significant. Perception is equally positively correlated with the Public Attitude. It has $27.8 \%$ capability to cause the favorable Public Attitude. It is statistically significant with the small effect. In conclusion, Trust is $29 \%$ positively correlated with the Public Attitude which is equally small effect but statistically significant.

Table 6. Coefficients ${ }^{\mathrm{a}}$

\begin{tabular}{|c|c|c|c|c|c|c|c|c|c|c|c|c|}
\hline \multirow[t]{2}{*}{ Model } & \multicolumn{2}{|c|}{$\begin{array}{l}\text { Unstandardized } \\
\text { Coefficients }\end{array}$} & \multirow[t]{2}{*}{$\begin{array}{l}\text { Standardized } \\
\text { Coefficients }\end{array}$} & \multirow[t]{2}{*}{$\mathrm{t}$} & \multirow[t]{2}{*}{ Sig. } & \multicolumn{2}{|c|}{$\begin{array}{l}95.0 \% \\
\text { Confidence } \\
\text { Interval for B }\end{array}$} & \multicolumn{3}{|c|}{ Correlations } & \multicolumn{2}{|c|}{$\begin{array}{l}\text { Collinearity } \\
\text { Statistics }\end{array}$} \\
\hline & B & Std. Error & & & & $\begin{array}{l}\text { Lower } \\
\text { Bound }\end{array}$ & $\begin{array}{l}\text { Upper } \\
\text { Bound }\end{array}$ & $\begin{array}{l}\text { Zero-o } \\
\text { rder }\end{array}$ & Partial & Part & Tolerance & VIF \\
\hline 1 (Constant) & 2.084 & .934 & & 2.231 & .027 & .244 & 3.924 & & & & & \\
\hline AWARENESS & .283 & .050 & .299 & 5.668 & .000 & .185 & .382 & .551 & .347 & .260 & .759 & 1.317 \\
\hline TRUST & .525 & .110 & .290 & 4.757 & .000 & .307 & .742 & .597 & .296 & .218 & .566 & 1.768 \\
\hline PERCEPTION & .506 & .113 & .278 & 4.489 & .000 & .284 & .728 & .600 & .281 & .206 & .550 & 1.817 \\
\hline
\end{tabular}

a. Dependent Variable: ATTITUDE. 


\subsection{Test of Hypothesis}

Three hypotheses were formulated in the study. The Test presented in Table 6 was used in testing the hypotheses. $\mathrm{H}_{1}$ which states that "consumers' awareness is not significantly related to the consumers' attitude toward Takaful services patronage in Kano Metropolis" was rejected. The calculated P-value $=0.000$ is less than or equal to 0.050 . $\mathrm{HO}_{2}$ which state that consumers' perceptions on Takaful services is not significantly related to the consumers' attitude toward Takaful service patronage in Kano Metropolis is found to be rejected. The calculated P-value $=0.000$ is less than or equal to $0.050 . \mathrm{HO}_{3}$ which also state that consumers' trust and confidence reposed on Takaful operators is not significantly related to the consumers' attitude toward Takaful services patronage in Kano Metropolis was rejected. The calculated P-value $=0.000$ is less than or equal to 0.050 . The overall result shows that consumers' awareness, perception. Trust and confidence reposed on Takaful operators significantly influence their attitude toward Takaful patronage. Therefore, Awareness, Perception and Trust are factors that determine consumers' Attitude on Takaful services patronage.

\section{Discussion of the Research Findings}

From the analysis it is discovered that the consumers' awareness of Takaful, perception on Takaful services and the trust and confidence reposed on the Takaful Operators have significant effect in influencing the consumers' attitude toward the Takaful patronage in Kano Metropolis, Nigeria. The effect is found to be averagely related the consumers' attitude. This implies that an attempt to increase the consumers' awareness of Takaful services create favorable attitude. Creating favorable consumers' perception toward the Takaful services has significant effect on positive attitude of consumers. Establishing and building consumers' trust of Takaful service providersrestore consumers' confidence of the Islamic insurance services as to be capable of meeting consumers' need of risk management tool.

The research, however, establishes that all the existing Takaful Operators, are offering Takaful service as either window operation or extension of conventional products. This is because, all the Operators in Kano Metropolis, focus on conventional insurance as their primary business. Consequently, this would create identity crises for the customers who are ill-informed about the Takaful services or who are ignorant of its existence. Similarly, this dual status of the Takaful operators can make it difficult to dissociate themselves from the bad reputation, of which the Nigerian conventional Insurance companies previously enjoyed. This calls for market strategic campaign which can distinguish the Takaful from the conventional insurance.

Therefore? Furthermore?, attitude of people, as noted, is a disposition which puts them into a frame of mind of liking or disliking an object, product or service; moving toward or away from it, understanding its factors that can build or change an attitude of customers is the motive of every provider of services or product, such as Takaful operators . These factors: Awareness, Perception and Trust are found to be so important to require the attention of the Takaful Operators in Kano Metropolis in particular and Nigeria in general. This would attract people toward Takaful services patronage.

\subsection{Conclusion and Recommendations}

The research discovers the factors that have significant influence on consumers' attitude toward Takaful patronage in Kano Metropolis, Nigeria. The analysis of consumers'Awareness about the Takaful services and its operators, the perception of consumers on Takaful services and its operators and their trust and confidence reposed on Takaful operators plays significant role of varying degrees on the consumers' attitude upon Takaful services patronage in Kano metropolis, Nigeria.

It is concluded that Awareness of Takaful services is paramount in shaping consumers' positive attitude on Takaful services patronage and as such an attention of Takaful operators is needed in building consumers' awareness to understand its benefits, operations, practice and its differences with the conventional insurance. Similarly the perception of consumers' on Takaful services and its operators is needed to be built to be favorable as it plays a significant role in pushing consumers to move toward the services rather than away from it. In addition the consumers' trust and confidence is needed to be established or restored so as Takaful services and its operators are seen as distinct from those investment companies whose services are perceived by consumers as unethical. Their operations should be transparent free from bias as some consumers perceived conventional insurance operation as a mere selfishness that always favor the company not the client in the event of payment due loss incurred.

Finally, it is recommended that there is need for attitudinal campaign in favor of Takaful which can be achieved through mass awareness campaign and advertisement employing all relevant marketing strategies. In a similarly way, the Takaful operators should modify their operations which would make it to be seen and perceived as 
transparent and professionals capable of meeting the needs of customers on risk management products. The operators should also work hard in differentiating themselves from the conventional insurance services which would build new reputation. Besides, they should win people trust and confidence.

\subsection{Suggestion for Further Research}

This study has discovered unique findings which portray public awareness of Takaful services, public favorable perception of Takaful services and public trust and confidence reposed on the Takaful Operators as factors that push people toward Takaful services patronage. There is need to replicate the study in other areas that shares some similarities with Kano state so as to establish the generalization of the findings.

\section{References}

Akpa, O. E. (2008). An Investigation of the Perceived Benefit of Hospitability and Tourism by Residents of Kano Metropolis. M.Sc. Dissertation, Unpublished B.U.K., Nigeria.

Ayuba, H. (2014). Non-Economic Factors Influencing the Islamic Insurance (Takaful) Services Consumption in Kano Metropolis, Nigeria; Unpublished M.Sc. Dissertation Submitted to the Department Business Administration and Entrepreneurship Studies, Bayero University Kano (BUK), Nigeria.

Bello, G. B., \& Ayuba, H. (2014). Perception of Consumers (Income-Earners) on Islamic Insurance (Takaful) Services' Consumption in Kano Metropolis, Nigeria: A Paper presented at the $1^{\text {st }}$ international conference of the International Institute of IslamicBanking and Finance, Bayero University, Kano, Nigeria, April 17-19, 2014.

Bichi, M. Y. (2004). Introduction to Research Methods and Statistics. Kano: Debis-co press and publishing company. Institute of Chartered Accountant of Nigeria (ICAN) Study Pack (2010). Business Communication and Research Methodology. Lagos: VI Publishers.

Kotler, P. (2000). Marketing Management (10th ed.). New Delhi: Prentice Hall of India Limited.

Kotler, P., \& Keller, K. (2005). Marketing Management (12nd ed.). New Delhi: Prentice Hall of India Private Ltd.

MdRazak, M. L., Idris, R., Yusof, M. M., Ja'apar, W. F., \& Ali, M. N. (2013). Acceptance Determinants toward Takaful Products in Malaysia. International Journal of Humanities and Social Science, 3(17).

Rahman, Z. A. (2009). Takaful: Potential Demand and Growth. Journal of Kau, Islamic Economics, 22(1).

Robbin, S. P., \& Judge, T. A. (2007). Organizational Behaviour (12nd ed.). New Delhi: Prentice Hall of India.

Schiffman, L. G., \& Kanuk, L. L. (2004). Consumer Behaviour (8th ed.). Bombay: Pearson Education Ltd.

Securities and Exchange Commission of Pakistan (SECP) Insurance Division. (2010). The Islamic Insurance (Takaful); how it works for you? A guide Book.

Taylor, D. Y. (2005). Ten Year Master Plan for the Islamic Financial Industry (Takaful).

Teas, K. (1993). Expectations Performance Evaluation and Consumer Perception of Quality. Journal of Marketing, 57(4), 18-35. http://dx.doi.org/10.2307/1252216

Wang, G., Dou, W., \& Zhou, N. (2008). Consumption Attitudes and Adoption of New Consumer Products; A contingency Approach. European Journal of Marketing, 42(1/2), 238-254. http://dx.doi.org/10.1108/03090560810840998

Yusuf, T. O., Gbadamosi, A., \& Hamadu, D. (2009). Attitudes of Nigerians toward Insurance Services: An Empirical Study. African journal of Accounting, Economics Finance and Banking Research, 4(4), 34-46.

\section{Copyrights}

Copyright for this article is retained by the author(s), with first publication rights granted to the journal.

This is an open-access article distributed under the terms and conditions of the Creative Commons Attribution license (http://creativecommons.org/licenses/by/3.0/). 